\title{
Ordem vermelha: filhos da degradação, entre a alta fantasia e a distopia
}

\author{
Ordem vermelha: filhos da degradação, between high fantasy and dystopia \\ Ordem vermelha: filhos da degradação, entre la alta fantasía y la distopía \\ Bruno Anselmi Matangrano*
}

\begin{abstract}
Resumo
Através das recentes discussões em torno do insólito ficcional, este artigo pretende mostrar o caráter inovador da construção do mundo de Untherak, em Ordem vermelha: filhos da degradação, de Felipe Castilho, obra que subverte as convenções da "alta fantasia" ao introduzir elementos da "distopia", por sua vez, modo narrativo que conquistou importante espaço na contemporaneidade por trazer discussões políticas e sociais despertadas pela forte onda conservadora da segunda década do século XXI, e cujas características básicas divergem bastante das teorias em torno da fantasia.
\end{abstract}

Palavras-chave: fantasia, distopia, insólito ficcional, Felipe Castilho, contemporaneidade.

\section{Abstract}

Capitalizing on recent discussions regarding the fantastic in fiction, this paper reflects on the innovation in the construction of the world Untherak, in Felipe Castilho's Ordem vermelha: filhos da degradação (Red order: sons of degradation). The novel subverts that which is conventionally called high fantasy by introducing elements of dystopia, a narrative mode that has gained increasing significance within contemporary fiction for spotlighting social and political issues - roused by the strong conservative wave in the second decade of the 21st century -, and whose basic features vastly diverge from fantasy theories.

Keywords: fantasy, dystopia, fantastic, Felipe Castilho, contemporaneity.

\section{Resumen}

A través de las recientes discusiones alrededor de lo insólito en la literatura, este artículo pretende mostrar el carácter innovador en la construcción del mundo de Untherak en el libro Ordem vermelha: filhos da degradação (Orden roja: hijos de la degradación), de Felipe Castilho, obra que subvierte las convenciones de la "alta fantasía" al introducir elementos de la "distopía", modo narrativo que ha conquistado importante espacio en la contemporaneidad por traer discusiones políticas y sociales despertadas por la fuerte ola conservadora de la segunda década del siglo XXI y cuyas características básicas divergen bastante de las teorías en torno a la fantasía.

Palabras clave: fantasía, distopía, insólito, Felipe Castilho, contemporaneidad.

No prefácio à edição portuguesa do Dicionário de lugares imaginários, de Alberto Manguel e Gianni Guadalupi, o escritor argentino comenta, despretensiosamente: "Talvez os lugares imaginários derivem simplesmente do desejo de ver para além do horizonte" (Manguel, 2013, p. xx). Nessa obra, Manguel e seu amigo italiano compilam, na forma de um guia, um milhar de locações fictícias, seja de cunho folclórico e mitológico, seja de cunho puramente artístico-literário, comentando-as como se fossem reais, e ilustrando-as com mapas e gravuras. Dentre os verbetes, abundam reinos e terras fantásticas, saídos de livros de fantasia, como, por exemplo, a Terra-Média de J. R. R. Tolkien (1892-1973), as Terras de Oz e de Ix, de L. Frank Baum (1856-1919), ou o universo de Terramar, de Ursula K. Le Guin (1929-2018), sem dúvida criados não apenas pelo desejo de ver para além do horizonte, mas de ver para além do possível, para além do passado, do presente e do futuro.

\footnotetext{
* Doutorando em letras na Universidade de São Paulo, São Paulo, SP, Brasil. (Dorcid.org/0000-0001-7914-0804. E-mail: bamatangrano@yahoo.com.br
} 
Nesse sentido, o ofício do escritor de literatura fantástica (em seu sentido mais amplo), e da fantasia, em particular, é sempre ver além do horizonte, extrapolando o dito "real", o que talvez aproxime as diversas vertentes do insólito ficcional ${ }^{1}$ umas das outras. Afinal, o que é a fantasia senão uma tentativa de criar outra realidade em outros mundos? A distopia, o space opera e o cyberpunk, por sua vez, não passam de tentativas de criar outras realidades em possíveis futuros; o retrofuturismo, em outros passados. E assim por diante.

As categorias do insólito ficcional, portanto, divergem de outras formas de literatura por partirem do mundo existente para criarem outros imaginários, enquanto as demais partem de elementos verídicos para tentar mimetizá-los e representá-los, mesmo sendo sabido que qualquer realidade literária será sempre ficcional, apesar dessa intenção de apreensão do real. Parece possível, portanto, ver como caráter unificador da maioria das tendências insólitas contemporâneas a criação de mundos possíveis, tendo como ponto de partida e divergência a realidade de hoje ou de outrora tão almejada por outras literaturas.

A despeito, porém, dessa convergência evidente entre as diversas formas de manifestação do insólito, dentro de uma classificação maior, torna-se inevitável a distinção de cada uma dessas categorias, a partir de suas especificidades, tornadas cada vez mais cambiantes na literatura contemporânea. Isso depende de como as diferentes categorias se sedimentam no imaginário e autores se sentem livres para ousar, subvertendo-as, distorcendo-as e mesclando-as para produzir possibilidades narrativas diversas, as quais tanto podem se apresentar como novas estéticas quanto podem melhor se adequar a determinadas realidades.

As categorias do fantástico partem muitas vezes do mitológico, do mágico-religioso e do imaginário para introduzir uma ruptura no tecido do real (como então considerado no momento da escrita) e produzir um efeito, seja de catarse, seja de maravilhamento, seja de amedrontamento, seja de alerta, seja de alegoria. Ainda assim, nem todas as suas vertentes trabalham com um imaginário já estabelecido. Na alta fantasia, especificamente, é comum a criação de um imaginário próprio, com seu conjunto de mitos, lendas, religiões, bem como um passado histórico, artístico e cultural. Esse imaginário se constrói a partir de algum contexto real, mas ao mesmo tempo delineado através de uma ruptura e de uma emulação, no intuito de criar algo novo. ${ }^{2}$

Com essa ideia em mente, pretende-se estudar neste artigo como o brasileiro Felipe Castilho, autor da série Legado Folclórico (composta por três volumes já publicados e por outro a sair) e dos roteiros das histórias em quadrinhos Imagine Zumbis na Copa e Savana de Pedra (finalista do Prêmio Jabuti), constrói, em Filhos da degradação (2017b), primeiro volume da série Ordem vermelha, um universo passível de ser visto tanto como alta fantasia quanto como distopia duas das categorias do Insólito de maior sucesso e difusão na contemporaneidade -, pois elementos de ambos os modos narrativos se emaranham no mesmo enredo. Porém, antes de se

\footnotetext{
${ }^{1}$ Entendido aqui como macrocategoria, de acordo com a proposta do grupo Nós do Insólito, coordenado pelo professor Flavio García (UERJ), e pelo GT na ANPOLL Vertentes do Insólito Ficcional. De maneira sucinta, García define "insólito", partindo de um artigo do pesquisador boliviano Renato Prada Oropeza, como sendo a "manifestação, em uma ou mais categorias básicas da narrativa - personagens, tempo e espaço - ou na ação narrada - sua natureza -, de alguma incoerência, incongruência, fratura de 'representação' - no sentido mais primário da mimesis - referencial da realidade vivida e experienciada pelos seres de carne e osso em seu real quotidiano, como, por exemplo, mimetiza a verossimilhança real-naturalista. Nesse sentido, pode-se dizer que existem, no mínimo, dois sistemas narrativo-literários: um real-naturalista, comprometido com a representação referencial da realidade extratextual; outro insólito -'não real-naturalista' -, que prima pela ruptura com a representação coerente, congruente, verossímil da realidade extratextual” (García. apud Matangrano, 2014, p. 181).

${ }^{2}$ Pensa-se em "imaginário" em seu sentido mais abrangente, conforme definido pelo teórico Jean-Jacques Wunenburger (2003, p. 10, tradução nossa), como "um conjunto de produções, mentais ou materializadas em obras, com base em imagens visuais (quadro, desenho, fotografia) e linguísticas (metáfora, símbolo, narrativa), formando conjuntos coerentes e dinâmicos, que depreendem desde uma função simbólica até o sentido de uma inserção de sentidos próprios e figurados que modificam ou enriquecem o real percebido ou concebido". O imaginário pode ser entendido como algo próprio de uma determinada civilização, um país, uma época, uma cultura, uma estética etc. No caso das narrativas insólitas, é comum a construção de um conjunto novo de referências a partir de uma mescla de elementos de diversas culturas, somados a criações totalmente novas. A Terra Média de Tolkien, por exemplo, parte do imaginário nórdico e celta, mesclado a dogmas e preceitos da tradição judaico-cristã, aos quais se soma, por exemplo, o conceito de hobbits (com seus hábitos, histórias, artes e costumes muito próprios), concebido pelo autor, criando uma nova visão que norteia o pensamento de suas personagens. O mesmo sistema de criação de mundo novo e de um consequente imaginário autêntico, a partir de um amálgama de referências variadas, será visto na obra de Felipe Castilho.
} 
discutir em pormenor a obra, convém explicar as características de cada uma dessas vertentes para, em seguida, analisar como Castilho as revisita e as transforma.

A fantasia se define pela existência de outra realidade, chamada para fins didáticos de "mundo secundário", sendo o "mundo primário", ou de partida, a própria realidade (Marques, 2015, p. 16). Esse outro mundo tanto pode ser um local totalmente distinto, com leis físicas, químicas, geográficas e biológicas próprias (como é o caso da Terra-Média de Tolkien), quanto um espaço alternativo dentro do mundo primário (como é o caso dos lugares onde vivem os bruxos na série Harry Potter, de J. K. Rowling). A proximidade e/ou a relação com o mundo primário definiria quando se trata de uma alta fantasia (pautada inteiramente no mundo secundário), ou de uma baixa fantasia (centrada no contato e diálogo entre os dois). ${ }^{3}$

Além da divisão entre alta e baixa fantasia, também há quem as classifique pela forma como o mundo primário e o secundário se relacionam, isto é, se há alguma ligação entre eles (e, caso haja, pelo grau de penetração do sobrenatural na realidade) ou se ambos existem de forma totalmente independente. Essas subcategorias denominam-se: fantasia intrusiva, fantasia de portal e fantasia imersiva, conforme teorizado por Carlos Alberto Nogueira Filho, a partir dos textos de Farah Mendlesohn:

A fantasia intrusiva é aquela em que o mundo real é perturbado pela irrupção do fantástico e, dependendo do grau [que] ela tem lugar no mundo primário, onde não há outros mundos ou portais separados, os mundos secundários residem dentro do primário. [...]. Na fantasia de portal encontramos uma relação entre o mundo primário e o secundário. Uma característica importante para este tipo de alta fantasia é o uso de portais para viajar de um lugar para outro. [...]. Por sua vez, a fantasia imersiva diz respeito à substituição do mundo primário pelo secundário, permitindo ao leitor mergulhar, diretamente e sem aviso prévio, em uma realidade diferente sem que essa cause qualquer tipo de estranheza (Nogueira Filho, 2013, p. 67).

Historicamente, é comum vincular a fantasia como uma derivação do maravilhoso, ${ }^{4}$ elemento utilizado para criar mundos possíveis de magia no intuito de encantar o leitor, em diálogo com o folclore, a mitologia e os contos de fadas, cujo formato até hoje é associado a esse modo narrativo. ${ }^{5}$ Todavia, na contemporaneidade, a fantasia passou a ser explorada de outras formas, com diferentes recursos, de maneira a construir mundos possíveis, onde o sense of wonder (ou simplesmente, a sensação de maravilhamento ou deslumbramento intrínseca ao maravilhoso) não está mais necessariamente no cerne de sua construção.

Obras do final do século XIX e do início do século XX, como The Wood beyond the World, de William Morris (1834-1896), Alice no país das maravilhas, de Lewis Carroll (1832-1898), A princesa e o Goblin, de George MacDonald (1824-1905), Peter Pan, de J. M. Barrie (1860-1937), a série de livros passados no universo ficcional de Oz, de L. Frank Baum (1856-1919), e até mesmo As Crônicas de Nárnia, de C. S. Lewis (1898-1963), poderiam ser apontadas na intersecção do maravilhoso com a nascente fantasia - que apenas se estruturaria nos moldes como hoje se conhece ao longo do século XX -, por se pautarem, sobretudo, pela noção de sense of wonder. Essas histórias, herdeiras do maravilhoso, não são exatamente altas fantasias, embora se passem majoritariamente em outros universos, uma vez que, nesses casos, mundo primário e secundário se relacionam por

\footnotetext{
${ }^{3}$ Importa destacar, como diz Carlos Alberto Nogueira Filho em sua dissertação de mestrado, que o "fato dos subgêneros serem chamados de alta ou baixa fantasia não tem nenhuma relação com a qualidade literária que um texto possa ter. Ao contrário, eles são usados para ilustrar o plano em que a narrativa acontece. Assim, se a história se passa totalmente, ou pelo menos em parte, no nosso mundo, é considerada baixa fantasia [...]. Por outro lado, a alta fantasia indica uma história que se passa totalmente em um mundo fictício, inventado e secundário" (Nogueira Filho, 2013, p. 16).

${ }^{4}$ Entende-se o conceito de "maravilhoso" aqui em seu sentido mais conhecido, isto é, como acontecimentos regidos por leis impossíveis e/ou inexplicáveis no que concebemos como realidade vistos com naturalidade e aceitação, conforme teorizado por Tzvetan Todorov em sua Introdução à Literatura Fantástica (2008), por sua vez, partindo dos estudos de Vladmir Propp em sua Morfologia do conto maravilhoso (2010).

${ }^{5}$ Assume-se aqui a preferência pelo termo modo narrativo (Ceserani, 2006) em oposição à gênero narrativo, para designar as diversas categorias associadas às vertentes do insólito ficcional, tais como a distopia e a alta fantasia, por se considerar tais categorias formas de se narrar, "passíveis de serem encontrados em diversas manifestações artísticas sem grandes restrições genéricas e/ou de suporte” (Matangrano, 2016, p. 250), tais como a prosa literária, HQs, cinema, séries televisivas, etc.
} 
meio da intrusão ou de um portal. A alta fantasia plena, por assim dizer, só surgiria no século XX, sendo O hobbit, de Tolkien, possivelmente sua primeira expressão. ${ }^{6}$

Para resumir, cita-se a tese de Marques, na qual se encontra a seguinte acepção para o termo fantasia, convergindo com o caminho traçado até aqui:

Propõe-se, portanto, a definição de um gênero aparentado com o maravilhoso e, consequentemente, com os contos de fadas, mas distinto deles, podendo-se, aliás, dizer que a fantasia é, simultaneamente, a exacerbação e a contraparte do maravilhoso. Exacerbação no sentido de que é o maravilhoso levado a outro nível, com a construção de um mundo coerente, diverso do Mundo Primário, ou seja, um mundo no qual as leis desse não explicam todos os fenômenos e no qual podemos encontrar seres e acontecimentos, aqui impossíveis. Contraparte porque enquanto o maravilhoso representaria uma espécie de integração, de harmonia, entre o "sobrenatural" e o Mundo Primário, a fantasia implica o outro, ou seja, ela exige a percepção das diferenças entre o "mundo real" e o "Mundo Secundário", que se tenha em conta o fato de eles não serem a mesma coisa, mesmo quando se interpenetram. $\mathrm{O}$ maravilhoso, em certo sentido, como se pode ver em relação aos contos de fadas, está mais preso ao "Mundo Primário", ainda é sua representação estilizada, enquanto a fantasia está livre para alçar voo e criar outro mundo (Marques, 2015, p. 16-17).

A fantasia, no entanto, é uma vertente em franca expansão, de modo que comumente surgem novas subcategorias para abarcar as produções atuais, sobretudo aquelas produzidas nas décadas finais do século XX e primeiros anos do novo milênio. Dentre estas, a vertente que talvez mais se distancie do maravilhoso das primeiras fantasias surge no final dos novecentos, denominada convencionalmente de dark fantasy (fantasia sombria), na qual elementos do horror/terror são incorporados na construção de um mundo não mais regido, necessariamente, por um grande bem (em oposição a um mal estereotipado), compondo assim um universo sem grandes maniqueísmos. Nesse tipo de fantasia, o medo como categoria estética, seja pautado no terror físico, seja no horror psicológico, se interpõe ao sense of wonder emprestado do maravilhoso. Um dos exemplos mais bem realizados dessa vertente é o filme O labirinto do fauno (2006), de Guillermo del Toro, no qual se exploram com maestria as potencialidades do elemento sobrenatural, que interpenetra a realidade histórica, ao mesmo tempo inserindo elementos do horror e do terror, seja pela violência explícita ocasionada em tempos de guerra, seja pela criação de monstros disformes e antropofágicos.

No caso de Ordem vermelha: filhos da degradação, subverte-se a alta fantasia de caráter imersivo ao construí-la através de recursos da distopia (por sua vez, derivada da Utopia e concebida no espírito da ficção científica, ao longo do século XX). Isso, num primeiro momento, contradiz a premissa básica de cada um desses dois modos narrativos: por um lado, a distopia prevê um futuro alternativo, de caráter decadente, e, muitas vezes, ultratecnológico, enquanto a fantasia imersiva (re)cria mundos pautados em passados distantes, medievalizantes ou não, em sua maioria num período equivalente à época pré-Idade Moderna, onde as leis bélicas imperam, regidas no fio da espada e, quase sempre, da magia, sem muito espaço para armas de fogo ou outras invenções típicas da modernidade. Essas características, é claro, são as mais básicas do modo narrativo em sua forma primeira, sem hibridismos com outras vertentes do insólito ficcional.

No caso em análise, não obstante, houve uma intenção declarada de fazer uma fantasia que, ao mesmo tempo, retomasse o conceito esperado desse modo narrativo e propusesse um deslocamento do lugar-comum para outras possibilidades, brincando inclusive com o imaginário tipicamente brasileiro (e, por consequência, fugindo um pouco dos estereótipos nórdicos, celtas e anglo-saxônicos, por tanto tempo onipresentes nas obras de fantasia, mesmo quando produzidas no Brasil), como esclarece o próprio autor em uma matéria publicada na Revista Omelete Box:

Coloquei na cabeça que minha história seria cortante, veloz e atormentada. Eu, que sempre retratei temas urbanos e sempre escrevi com cinismo e sarcasmo [...], descobri que

\footnotetext{
${ }^{6}$ Para um maior aprofundamento nos tipos temáticos de fantasia na contemporaneidade e, em particular, suas manifestações na literatura brasileira, ver os capítulos "A Fantasia no espaço urbano" e "Nos territórios da Alta Fantasia" do livro Fantástico Brasileiro: O Insólito Literário do Romantismo ao Fantasismo (Matangrano e Tavares, 2018).
} 
precisaria mergulhar nas partes mais sujas da fantasia. Queria fazer o meu Trainspotting na Terra Média, o meu Cidade de Deus em Westeros, ao mesmo tempo em que procurava me afastar da Terra Média e de Westeros (Castilho, 2017a, p. 42).

Nesse sentido, Castilho ainda esclarece numa entrevista concedida ao jornal O Extra, em 29 de janeiro de 2018, sua vontade de manter esse diálogo com a tradição e trazer elementos novos, para mostrar "outro lado" dos mundos de fantasia, privilegiando as classes menos favorecidas em detrimento dos nobres que habitualmente protagonizam obras desse tipo:

Acho que o livro começa com um aceno para todos os grandes autores da fantasia que continuarão encantando novos leitores para sempre, mas depois parte para um rumo que me motivou demais a criar cada beco sujo de Untherak: eu sentia falta de me sentir parte da periferia dos reinos fantásticos. [...] normalmente os lugares miseráveis dos livros de high fantasy [Alta Fantasia] acabam sendo um cenário temporário, pois o herói e a heroína logo partem dali para alguma aventura incrível. Nos meus livros do Legado Folclórico, eu mostrei o meu Brasil através de seus mitos e lendas urbanas, e na Ordem vermelha eu apresento parte dos nossos problemas políticos e sociais sendo criados através da espada e de uma magia eclipsada pelo obscurantismo (Matangrano, 2018, sem página).

Embora híbrida, não se trata aqui, obviamente, de uma obra de dark fantasy, pois Felipe não trabalha com elementos de horror (apesar de algumas cenas apontarem nessa direção ao suscitar medo e criar uma atmosfera opressora), mas sim de uma inovadora "fantasia distópica",7 termo aqui proposto para analisar a obra enquanto subversão da própria ideia de distopia (a rigor, sempre partindo de uma pessimista premissa futurista para a realidade) e de alta fantasia. De certa maneira, isso acontece pelo fato de ele realocar uma sociedade distópica em um mundo secundário singular, regido por magia, dentro de universo fantasista préindustrial; enquanto redireciona o sense of wonder da fantasia para um "sentido de alerta" ou "aviso de incêndio", sobre o qual se falará a seguir, além de apresentar uma possibilidade de sociedade decadente regida por governo teocrático ditatorial.

Esse hibridismo foi proposital, mas também consequente às escolhas (partindo de um possível regime monárquico absolutista) e referências (de ambos os modos narrativos) de Castilho, surgindo de forma "natural", ao tentar mostrar o lado dos marginalizados, via de regra excluído nas fantasias tradicionais, como atesta o autor:

Por mais que o livro tenha essa sombra distópica, ela foi naturalmente evocada quando defini usar esses elementos de poder absolutista centralizados em Una, no General e na Centípede. Daí foi um pulo para eu me ver cercado de questões que as minhas distopias preferidas abordam. Admirável Mundo Novo, Fahrenheit 451 (meu favorito), 1984... estão todos ali, ao lado das minhas referências no insólito - Ursula K. Le Guin, Terry Pratchett, Philip Pullman. [...] posso dizer que essa foi a minha forma de provocar a ideia ridícula de uma nação que ignora a existência do plural e do diverso. Quando o Estado decide que só existe uma escolha possível, uma linha de pensamento, uma forma de economia e uma orientação sexual, cabe a todos os excluídos se revoltarem, sim (Matangrano, 2018, sem página).

Mas, afinal, o que caracteriza uma distopia? E por que parece tão inovador introduzir elementos desse modo narrativo em uma fantasia?

Para começar, pensa-se em algumas definições bastante sucintas, de pronto divergentes em relação ao texto de Castilho, pois consideram como intrínseco ao modo distópico um cenário no futuro. Segundo o verbete "Ficção Científica", de Gérard Klein (2009, p. 126), do Dicionário das Utopias, organizado por Michèle Riot-Sarcey, Thomas Bouchet e Antoine Picon,

\footnotetext{
${ }^{7}$ Propõe-se essa classificação por analogia a outras subcategorias da fantasia nascidas da junção de elementos de uma ou mais vertente do insólito ficcional justapostas ao conceito propriamente dito de fantasia. Assim, surgem a própria ideia de "fantasia sombria", já mencionada, mas também "a science fantasy ou fantasia científica", na qual elementos da ficção científica são aplicados a um mundo de fantasia; a fantasia histórica, em um hibridismo entre a fantasia e o romance histórico, não raro passada no século XIX ou no período das grandes guerras, mas podendo se ambientar em qualquer época; a steam fantasy, com ambientação steampunk, [...] dentre outras formas concebidas à medida que escritores contemporâneos desejam criar novos cenários para suas histórias" (Matangrano e Tavares, 2018, p. 234). Logo, a noção de "fantasia distópica" parece natural à medida que os dois modos narrativos de maior sucesso na atualidade passam a se imbricar.
} 
distopia "seria a descrição de um mundo futuro onde as coisas correram mal a partir da exacerbação nociva de um traço da nossa sociedade”. Mas, acima disso, para Leomir Hilário, distopias também "são a denúncia dos efeitos de poder ligados às formas discursivas" (Hilário, 2013, p. 206). Ou seja, por um lado, a narrativa distópica normalmente se desenvolve num futuro possível, caso algo do presente da escrita saia do controle. Isso não é o caso do livro de Castilho, situado em um mundo secundário pré-tecnológico, cujo passado, contudo, teria sido glorioso em comparação ao decadente presente da narrativa. Por outro lado, é igualmente intrínseco ao enredo distópico o forte caráter de denúncia e crítica social (este sim, o cerne do universo de Ordem vermelha). Nesse sentido também comenta Leomir Hilário:

As distopias problematizam os danos prováveis caso determinadas tendências do presente vençam. É por isso que elas enfatizam os processos de indiferenciação subjetiva, massificação cultural, vigilância total dos indivíduos, controle da subjetividade a partir de dispositivos de saber etc. A narrativa distópica é antiautoritária, insubmissa e radicalmente crítica. As distopias continuam sendo utopias, no sentido que Jacoby (2001, p. 141) lhe deu, isto é, não apenas como a visão de uma sociedade futura, mas como uma capacidade analítica ou mesmo uma disposição reflexiva para usar conceitos com a finalidade de visualizar criticamente a realidade e suas possibilidades (Hilário, 2013, p. 206).

Diante disso, fica claro que Filhos da degradação apresenta um universo onde essas duas categorias se mesclam, como se mostrará a seguir. Alude a outros mundos de fantasia clássica, tanto por retomar raças mitológicas, como gigantes, anões e elfos (ao lado de raças criadas dentro do próprio universo ficcional da série, como os kaorshs e os sinfos), quanto por propor outra realidade, sem relação aparente ou explícita com o universo real. Ao mesmo tempo, conversa com elementos da distopia ao propor uma cidade teocrática autoritária, onde se cerceia a liberdade, proíbem-se as artes, a leitura e a escrita, especificamente, e a liberdade de expressão, de modo geral, e impõe-se uma religião única a uma população em regime de servidão ou, no máximo, de semiliberdade (segundo terminologia da própria obra). Sem trazer nenhum caráter futurista, Castilho constrói uma sociedade muito diferente, mas em indiscutível diálogo com a brasileira, cheia de intolerância, na qual religião e governo se fundem de maneira perigosa. ${ }^{8}$

Se por um lado grande parte da crítica considera a fantasia propositalmente descolada da realidade (tese sustentada pelo próprio Tolkien), a distopia, por outro, é inequivocamente uma crítica a essa mesma realidade. ${ }^{9}$ No caso da obra de Castilho, o fator de crítica da distopia parece se sobrepor aos demais elementos, pois todo o enredo gira em torno da formação de um grupo para combater o sistema político vigente, atualizando a parâmetros contemporâneos - e, por conseguinte, conferindo-lhe um caráter alegórico -, a noção de fantasia, durante muito tempo entendida como uma literatura escapista por determinada crítica, a exemplo do trecho abaixo de um estudo do pesquisador alemão Moritz Baßler:

\footnotetext{
${ }^{8}$ Não parece casual a obra de Felipe Castilho surgir no mesmo ano em que vemos serem publicadas outras de evidente viés político como Ninguém nasce herói (Ed. Seguinte, 2017b), de Eric Novello, esta sim, uma distopia aos moldes tradicionais passada na São Paulo contemporânea, alguns anos no futuro, na qual um político fanático-religioso assume o comando do Brasil, criando um governo bastante opressor, sob um véu populista. Com isso, vai ao encontro da análise de Leomir Cardoso Hilário proposta em seu artigo "Teoria Crítica e Literatura: a distopia como ferramenta de análise radical da modernidade" (2013), no qual identifica no modo narrativo distópico uma pertinente forma de crítica social a determinados governos, em especial aqueles pautadas na intolerância e na opressão. Não parece coincidência, por isso, que obras como as de Novello e Castilho, surjam no mesmo momento histórico em que vemos fortes ondas conservadoras alcançando poder, em sua maioria estreitamente ligadas à censura às artes e a algumas religiões, a partir das quais os intolerantes justificam seu comportamento, violências e opressões. Em caminho semelhante, mas de maneira bem mais explícita, Samir Machado de Machado, em seu romance histórico de espionagem Homens elegantes (Ed. Rocco, 2016), também trabalha temas como intolerância, censura e opressão, dando, por exemplo, a seu terrível vilão, um nobre antiquado e bastante preconceituoso, o nome de uma das figuras políticas mais intolerantes e controversas do atual cenário político brasileiro.

${ }^{9}$ Nos últimos anos, obras distópicas têm encontrado cada vez mais espaço e sucesso na mídia, em diversos formatos, tanto literários quanto cinematográficos ou televisivos. Sucessos recentes como as séries de livros tornadas filmes Divergente e Jogos vorazes ou séries de serviço streaming como a brasileira $3 \%$ e a polêmica The handmaid's tale, baseada em livro homônimo de Margaret Atwood, mostram que tempos de grandes tensões político-sociais não raro levam a um maior consumo de obras questionadoras do sistema, acionando um "aviso de incêndio". Para um aprofundamento nessa questão e nas recentes produções distópicas brasileiras, recomenda-se o capítulo "Futuros sombrios e a febre das distopias", do livro Fantástico Brasileiro: o insólito literário do romantismo ao fantasismo (2018).
} 
[...] histórias e mundos de fantasia não são alegorias. Evidentemente, tudo em qualquer mundo imaginado pode ser transferido e comparado com o nosso, mas não estamos tratando disso aqui, ou não estamos mais. Tolkien (1994) já ficava impaciente quando se afirmava que O senhor dos anéis seria uma alegoria à luta contra os nazistas [...]. Mundos de fantasia são simulações, sim, mas não de aspectos do nosso mundo. Aqui, se tenta muito mais construir um mundo novo, atrativo, independente e especialmente habitável, um bem pelo qual, claramente, há uma alta procura no nosso tempo. Pois o mundo com suas regras, a diegese, é o produto decisivo aqui, mais do que as histórias que se desenrolam nele. Elas são cambiáveis ou, muito mais, como nas séries episódicas à la Simpsons e Tatort, podem ser multiplicadas em série infinitamente, e repito: pelo próprio autor, mas também por times de sucessores e pelos receptores. Sua fanfiction, via de regra, se mantém fiel aos parâmetros diegéticos; pois são justamente eles que os fãs adoram (Baßler, 2016, p. 92-93).

À parte certo preconceito subjacente à teoria de Baßler e de outros críticos, que não apenas comumente apontam o embate elitista e contraproducente entre alta literatura e literatura de massa ou de entretenimento como também consideram simples escapismo a maioria dos modos narrativos do Insólito, de fato há certa negação à leitura alegórica em muitas obras de fantasia, como é o caso dos livros de Tolkien. No entanto, isso não configura uma regra de conduta de toda e qualquer narrativa da vertente; antes parece uma característica frequente em textos da segunda metade do século $X X$, pouco a pouco relativizada conforme a fantasia se popularizou e se diversificou entre autores, público e mercado.

Em Castilho, a leitura política - confirmada e incentivada pelo próprio autor, inclusive - não apenas é uma possibilidade, como se mostra inevitável, considerando a ênfase dada a essas questões na própria formação do mundo de Untherak, uma cidade-estado governada por uma deusa tirânica, um general cruel e um conselho não-eleito de magos-cientistas sádicos. Ao longo da narrativa, acompanhamos um grupo de heróis tentando pôr fim à tirania, libertando, assim, o povo do regime de pseudoliberdade. Dito isso, interessa passar agora à discussão mais pormenorizada da trama para mostrar como o autor faz uso desses elementos da fantasia e da distopia em seu romance.

O livro se abre de maneira singular com uma espécie de resumo da origem do universo de Ordem vermelha, cujo tom e ambientação preparam o leitor para os capítulos seguintes. Intitulado "A fúria dos seis e o surgimento de Una", esse introito é um texto cosmogônico aos moldes da Teogonia grega, do Gênesis judaico-cristão e do início de O Silmarillion, de Tolkien -, conhecido de cor por cada habitante de Untherak. Como seus congêneres, esse texto se inicia com a narração do surgimento do mundo:

No princípio, não havia nada, somente os Seis Deuses. E, em toda a sua bondade, eles teceram o manto dos céus - um lado escuro e cravejado de pedras preciosas, o outro, claro e com uma pepita de ouro incrustada. Os Deuses o estenderam acima da superfície que abrigaria as águas, os montes e tudo mais que a vasta imaginação dos Seis ousasse materializar. Diante de tantas maravilhas, os Deuses acharam por bem criar protetores para cada uma delas. Para as montanhas, criaram os gigantes. Altos e fortes, capazes de limpar os picos enevoados e de tratar a tundra. Para as cavernas, os anões, pequenos mas resistentes, como os valiosos minérios que lá se formavam. Para guardar as águas e tudo que fluía, foram criados os gnolls. Silenciosos como a chuva, velozes como os rios. Para os bosques repletos de frutas e flores, os sinfos. Leves como o pólen carregado pelo vento, eles seriam os mensageiros da magia invisível. Para os terrenos rochosos e as selvas fechadas, os kaorshs. Altivos e esguios, preparados para transpor obstáculos e responsáveis por dar cor ao mundo. Os humanos receberam as planícies. Fortes e de boa saúde, eles cuidariam do solo e amariam aquilo que lhes era dado (Castilho, 2017b, p. 7).

Esse trecho traz os acontecimentos anteriores à suposta origem de Una, surgida dos seis deuses primordiais criadores dos céus, da terra e das raças que nela habitam. Embora esse tipo de recurso genético não esteja presente em todas as fantasias, é bastante frequente narrar, em algum momento da trama, ou até mesmo em obras derivadas, se não a origem do mundo, ao menos a origem de um povo, uma cidade, uma civilização. Em O Sobrinho do Mago, primeira das sete Crônicas de Nárnia, de Lewis, o momento da criação não aparece no 
início, mas nos capítulos 8 e 9, quando as personagens adentram um local escuro sem absolutamente nada. Então ouvem um canto e pequenas luzes começam a surgir, numa alusão bíblica ao Verbo criador. O canto persiste e Aslam, o leão-deus da mitologia narniana, surge em sua potência. É dele a voz que canta e constrói o mundo, evocando, pouco a pouco, o sol, a grama, os animais, as árvores etc. (Lewis, 2005, p. 56).

Por sua vez, n'O Silmarillion de Tolkien o leitor descobre que antes do surgimento do continente Terra Média, onde se passam os acontecimentos de O Senhor dos Anéis e $O$ hobbit, havia outro, Beleriand, e, muito antes, nada havia, salvo uma entidade. No princípio, só havia Eru Ilúvatar, de cujos pensamentos surgem outras divindades menores e, em seguida, a Arda (o mundo propriamente dito), logo povoada por animais e plantas, bem como por raças sencientes. Tal como em Castilho, o livro abre-se numa emulação do texto bíblico, listando o surgimento de tudo a partir do nada:

Havia Eru, o Único, que em Arda é chamado de Ilúvatar. Ele criou primeiro os Ainur, os Sagrados, gerados por seu pensamento, e eles the faziam companhia antes que tudo o mais fosse criado. E ele lhes falou, propondo-lhes temas musicais; e eles cantaram em sua presença, e ele se alegrou. Entretanto, durante muito tempo, eles cantaram cada um sozinho ou apenas alguns juntos, enquanto os outros escutavam; pois cada um compreendia apenas aquela parte da mente de Ilúvatar da qual havia brotado e evoluía devagar na compreensão de seus irmãos. Não obstante, de tanto escutar, chegaram a uma compreensão mais profunda, tornando-se mais consonantes e harmoniosos (Tolkien, 2003, p. 3).

Já a origem da Westeros de George R. R. Martin apresenta-se de forma muito fragmentária ao longo dos cinco volumes até agora lançados de As Crônicas de Gelo e Fogo e nunca num contexto mitológico-religioso; no entanto, no livro pseudo-histórico O Mundo de Gelo $\mathcal{E}$ Fogo, escrito em parceria com Elio M. García Jr. e Linda Antonsson, essa gênese é apresentada, não em termos míticos, como modelos supracitados, mas, ao contrário, buscando emular certo rigor historiográfico e arqueológico. Afinal, o livro se apresenta como "documento histórico", funcionando como um suplemento ficcional para se entender o mundo da série principal. Por esse motivo, em seu parágrafo inicial, não é dito o que havia "no princípio", embora se especule uma data de formação do mundo, mas quando a civilização conhecida começou, conforme trecho abaixo:

Ninguém pode dizer com certeza quando o mundo começou, mas isso não impediu muitos meistres e homens eruditos de procurar a resposta. Há quarenta mil anos, como alguns sustentam, ou talvez um número tão grande quanto quinhentos mil - ou mesmo mais? Não está escrito em nenhum livro que conhecemos, pois, na primeira era do mundo, a Era da Aurora, os homens não eram letrados (Martin, García Jr., Antonsson, 2014, p. 5).

Isso demonstra que, ao escolher abrir sua obra com um texto teogônico no qual conta a origem das raças de seu universo - sendo o próprio conceito de múltiplas raças sencientes uma constante em obras de fantasia -, Castilho opta pelo diálogo com as vertentes mais tradicionais da alta fantasia. Todavia, isso logo é subvertido: ao contrário de seus congêneres anglófonos, o momento de criação de seu mundo desvirtua-se do tom plácido da citação anterior com a introdução da oração adversativa: "No entanto, o que era paz se tornou guerra" (Castilho, 2017b, p. 7), à qual se segue a descrição de uma série de conflitos entre as raças antes enumeradas, suscitados por inveja e ambição. Tal situação, porém, não tarda a ser punida pelas seis divindades, culminando em um "futuro" (no caso, correspondente ao presente da narrativa principal) de decadência e degenerescência tipicamente distópico:

Os Deuses, ofendidos e decepcionados, enviaram pragas como punição para criaturas tão insatisfeitas. Dessa forma, as florestas passaram a ser habitadas por monstros e outras abominações; o ar cheirava a fumaça e morte; os rios tinham a cor vermelha do sangue daqueles que pereceram nas batalhas. [...] Após tanta dor e lamento, o mundo se reduziu a um deserto, e esse deserto recebeu o nome de Degradação. Sobrou apenas um único pedaço de terra habitável, aos pés do monte Ahtul, próximo aos Grandes Pântanos formados durante a guerra. No cume, os Deuses combatiam os últimos dos mesquinhos gigantes, que se revoltavam contra os castigos recebidos. Então, com as mãos repletas do sangue vermelho dos desobedientes, os Seis perceberam que tinham se tornado tão cruéis 
quanto aqueles que não honraram suas bênçãos. Assim, eles decidiram tornar-se algo novo, sem falhas. Assim, eles decidiram tornar-se um só. Assim, surgiu a deusa de seis faces, a deusa Una (Castilho, 2017b, p. 8).

Após isso, o leitor se depara com um mundo que pouco tem a ver com o lugar descrito no início desse texto pseudo-religioso, cujo foco é, antes de tudo, mostrar a maldade intrínseca aos povos e a necessidade de louvar a deusa Una, nascida da compaixão dos seis deuses, após sua vingança contra as raças sencientes. O choque é imediato: se o livro começa num tom sacro e idílico, quando descrita propriamente Untherak se mostra um lugar nocivo, hostil, opressivo, desértico e, ao mesmo tempo, pantanoso, ao redor do qual sobrevivem pessoas, criaturas esquálidas e seres venenosos e malignos. Tal lugar é regido, já há mil anos, pela deusa soberana, por seu braço-direito, o General Proghon, um ser também aparentemente imortal, e pela Centípede, um conselho de criaturas eternamente escondidas por mantos negros, cuja real identidade nunca é revelada, pois os poucos a descobrirem-na não sobrevivem para contar. Feita essa primeira apresentação, o leitor é levado para a periferia do reino, onde o povo trabalha muito em prol da riqueza do governo e em detrimento de si mesmo. Quase tudo é vetado no território governado por Una. A maioria dos habitantes da cidade vive em celas, dada sua condição servil, enquanto o restante é relegado aos Assentamentos, espécie de favela, marcada pela falta de infraestrutura, saneamento e segurança básicos, como visível na descrição abaixo:

Ficou claro que os barracos e as casas mal-ajambradas no início da subida do morro tinham pegado fogo, algo corriqueiro nos Assentamentos. Quando isso acontecia, os moradores saíam do local, as casas eram reconstruídas e a encosta do morro, refeita - o que não ocorrera dessa vez. Tempos difíceis, que ficariam ainda piores (Castilho, 2017b, p. 11-12).

Nesse contexto de completa opressão e precariedade - tão distintas da atmosfera épica e gloriosa típica da alta fantasia -, fermenta-se uma revolta, iniciada por uma bastante reduzida resistência, em razão do medo que impera e congela a população, sufocando as poucas tentativas de protesto ou reivindicação de direitos. Esses Assentamentos funcionam como elemento de brasilidade, pois sua presença "dialoga com nossa tradição literária e cinematográfica, na qual não se encontram cavaleiros em cavalos brancos, mas sim pessoas humildes lutando pelo dia-a-dia" (Matangrano, Tavares, 2018, p. 253).

Aos poucos, revela-se que em Untherak qualquer forma de arte é proibida, assim como o seu registro, a despeito do fato de cada uma das quatro principais raças nativas terem em uma arte específica parte da formação cultural de seu povo.

A primeira dessas raças, os anões, formou sua cultura milenar em torno da escultura e da arquitetura por serem habilidosos na construção e na ourivesaria. São o povo de maior longevidade de Untherak, assim como as artes por eles praticadas. Após a tomada do poder por Una e pela Centípede, os anões se viram obrigados a construir apenas o necessário para o governo e a esculpir apenas em louvor à grande-deusa soberana. Suas tradições, no entanto, permanecem escondidas nos detalhes da velha cidade, o que despertará em Harun, um dos líderes da resistência, o desejo de recuperar a antiga glória de seus ancestrais.

Os kaorshs, por sua vez, um povo alto e esbelto, cuja fisiologia permite mudar a cor da pele, como um camaleão ou uma sépia - e, além disso, mudar também a cor daquilo que tocam, quando e se assim desejam -, louvam as cores. Para eles, as artes mais importantes são o desenho e a pintura, pois através delas podem preservar imagens e padrões. Também expressamente proibidas pelo governo, estas são artes das mais condenadas, sobretudo porque uma das cores, o vermelho, por evocar o sangue e o fogo, foi banido. Com isso, pouco a pouco, os kaorshs foram se esquecendo do poder da imagem, embora isso esteja entranhado em sua própria essência e corpo em algum nível, pela possibilidade de pintarem a si mesmos.

Já a raça assexuada dos sinfos, aparentada das plantas, preza a efemeridade e a leveza da dança e da música. Como suas vidas são muito breves, em geral cerca de treze anos, possuem uma relação bastante diferente com a temporalidade, e não surpreende, portanto, sua dedicação às chamadas "artes do tempo", em detrimento das "artes do espaço", como a pintura e a 
escultura. ${ }^{10}$ A cultura dos sinfos, por outro lado, consegue de certa forma preservar melhor sua arte, já que é mais difícil proibir a dança ou a música, atos inapreensíveis, inconfiscáveis, presentes no patrimônio imaterial da espécie, transmitido dos mais velhos aos mais novos; além disso, o próprio governo autoriza algumas canções, utilizadas para treinamento de certa espécie exótica untherakiana de gado, cujo temperamento apenas os sinfos conseguem apaziguar. Talvez por isso, das quatro raças, os sinfos tendam a ser os mais felizes.

Por fim, aos humanos resta a nobre arte de contar histórias (isto é, a literatura, em sua acepção primeira), algo terminantemente proibido: a única narrativa permitida em Untherak é "A fúria dos seis e o surgimento de Una", anteriormente comentada. Proíbe-se a escrita a quase todos, salvo aos responsáveis pelo registro contábil e legal. Não há livros em Untherak, assim como não há pinturas. Mas o povo conta histórias, claro, apesar da proibição.

Por tudo isso, a manipulação da deusa-governante deformou a memória coletiva dos habitantes de Untherak, após também coibir outras formas de cultos quando não em seu próprio louvor. Ainda assim, mesmo sem grande possibilidade de resgatar antigas tradições, as narrativas orais persistem. Há rumores dos tempos antigos. Há relatos de lugares distantes. Existem resquícios de lembranças, contadas de pai para filho, entre cada uma das raças, de modo que, a despeito de todas as proibições, mesmo o mais pacífico dos moradores da cidadeestado murmure na relativa segurança de sua casa nos Assentamentos ou de sua cela alguma lenda antiga, de outros tempos, quando havia outros deuses, outras crenças - quando cada povo podia praticar a sua arte, sem censura, sem punição. Dentro do espírito da distopia, isso parece sintomático como forma de protesto alegórico diante do cenário sociopolítico mundial, sobretudo num momento em que o Brasil assiste o fechamento de exposições e a proposição de projetos de leis com objetivo de tolher a liberdade de expressão.

Nesse sentido, a narrativa de Untherak retoma uma questão apontada por Claude Mouchard no verbete "Contra-Utopias" do já mencionado Dicionário de Utopias, como uma característica desse tipo de narrativa: "Estas ficções trabalham o próprio tempo. Passado, presente, futuro revertem uns nos outros. Tais antecipações, mesmo quando alegam um futuro longínquo, são feitas não para fugir da história que se aproxima, mas para a explorar" (Mouchard, 2009, p. 88-89).

Fica explícita também a importância da própria linguagem enquanto ferramenta de resistência, construção e manipulação de memória e imaginário, por um lado, e enquanto forma de opressão, por outro. A importância da linguagem, curiosamente, parece um elo entre fantasia e distopia: em histórias distópicas, comumente a arte e outros tipos de discurso ajudam a minar o poder autoritário - apesar de e por serem quase sempre proibidas -, enquanto nas fantasistas é comum se valorizar o poder da palavra por seu potencial mágico (muitas vezes a magia está na própria palavra; o termo é a coisa e a coisa faz o encanto, como acontece em Harry Potter e também nos livros da saga de Eragon, de Christopher Paolini, para citar apenas dois exemplos). Além disso, o próprio mundo secundário, por ser imaginário, constrói-se e existe apenas na própria linguagem, tanto quanto o universo futurista da distopia também se estrutura pelo discurso, sem ancoragem direta no mundo dito real. Isto é, não é possível mostrá-los, só descrevê-los, como aponta Tainá Thiés, no trecho abaixo:

É sobre a linguagem que os mundos da fantasia são construídos, pois não há condições de atingir o leitor e explicar-lhe como adentrar a este novo espaço literário senão através da referência. Na literatura, nada há fora da linguagem. Se o autor deseja criar um universo em que há três luas, onde uma é vermelha, outra verde e outra azul, mesmo assim ele não escapará de utilizar o referencial linguístico, visto que os signos "lua", "vermelha", "verde" e "azul" necessitam ser compreendidos pelo leitor (Thiés, 2012, p. 25).

\footnotetext{
${ }^{10}$ Pensa-se no conceito de artes do tempo e do espaço, conforme teorizado por Gotthold Lessing (1729-1781) em seu livro Laocoonte ou sobre as fronteiras da Pintura e da Poesia (2011), isto é, respectivamente, artes impalpáveis e intangíveis, cuja fruição só pode se dar em determinada ordem e intervalo (o tempo de ouvir uma música ou assistir uma dança, por exemplo), em contraste com artes apreensíveis em uma olhada (como uma pintura), exigindo no máximo o movimento dos olhos ou do próprio corpo do espectador para a percepção de detalhes (o que lhes confere um aspecto espacial) e possibilitando o retorno a um ponto de observação inicial a qualquer momento sem sofrer com a interferência do tempo (algo impossível nas artes do tempo, pois o momento de execução de cada performance é único).
} 
O livro de Castilho parece pretender justamente louvar a linguagem, enquanto forma de construir o mundo, a memória, a identidade ou a arte. Graças à linguagem, essas instâncias tornam-se impossíveis de se censurar, permitindo a sobrevivência da tradição. A partir dela, a resistência à tirania de Una começa.

Assim, Untherak apresenta-se como um mundo onde as liberdades de expressão, artística e religiosa foram tolhidas, remetendo a outras distopias, como Fahrenheit 451, de Ray Bradbury (1920-1912), na qual livros são proibidos, uma realidade ameaçadora para o mundo contemporâneo, dado o avanço das ondas conservadoras defensoras da censura e da manipulação de informações. A diferença se mostra por Castilho trabalhar o tema em uma roupagem épica, mágica, mítica, pré-tecnológica, em um cenário de Fantasia e não em um mundo futurista, soando como uma "profecia ameaçadora". ${ }^{11}$ Sua crítica se apresenta de forma explícita, mas sutil, como demanda a delicadeza do tema. Dessa maneira, o livro pode ser lido enquanto distopia, segundo a ideia de que esta deve obrigatoriamente combater algo do momento presente, como comenta Hilário:

A narrativa distópica não se configura, deste modo, apenas como visão futurista ou ficção, mas também como uma previsão a qual é preciso combater no presente. Ela busca fazer soar o alarme que consiste em avisar que se as forças opressoras que compõem o presente continuarem vencendo, nosso futuro se direcionará à catástrofe e barbárie. Por isso, concebo a distopia como aviso de incêndio (Hilário, 2013, p. 206-207).

Mais do que simplesmente um aviso, Hilário também aponta a análise e os questionamentos, propostos pela narrativa distópica, a pretensas utopias, por trás das quais comumente há segundas intenções mascaradas (como de fato acontece sob a bela fachada de Una):

O objetivo das distopias é analisar as sombras produzidas pelas luzes utópicas, as quais iluminam completamente o presente na mesma medida em que ofuscam o futuro. Elas não possuem um fundamento normativo, mas detêm um horizonte ético-político que lhes permite produzir efeitos de análise sobre a sociedade. As distopias ou as utopias negativas "expressam o sentimento de impotência e desesperança do homem moderno assim como as utopias antigas expressavam o sentimento de autoconfiança e esperança do homem pós-medieval" (Hilário, 2013, p. 205, grifos do autor).

É justamente a partir desse "sentimento de impotência e desesperança do homem moderno" (tanto passível de ser associado ao escritor brasileiro contemporâneo quanto aos personagens de Ordem vermelha) que um grupo de habitantes de Untherak decide fazer algo a respeito para mudar a situação vigente. Apesar do uso da força e de armas, inevitáveis na trama não apenas por uma questão de combate, mas de defesa e proteção, o grupo se valerá também do resgate da arte, das tradições e da memória coletiva como forma de luta e resistência silenciosa no intuito de implodir o sistema por dentro.

Encabeçando essa resistência, além de Harun, o anão negro que se junta ao grupo, outros dois importantes personagens de Filhos da degradação são Aelian e Raazi, a partir dos quais a trama se desenrola. Aelian é um jovem servo humano. Isso significa que possui uma tatuagem no rosto marcando sua servidão e que não tem total liberdade de ir e vir por Untherak; no entanto, o jovem nem sempre segue as leis. Dado seu vício em jogos de azar, e a habilidade furtiva e acrobática de quem cresceu sozinho em uma cidade hostil, de arquitetura caótica, Aelian aprendeu a fugir escalando torres e andando por telhados. Com isso, consegue roubar comida quando necessário e acaba se envolvendo com outros habitantes praticantes de ações ilegais, dentre os quais a Aparição, personagem misteriosa que começa a arrebanhar pessoas questionadoras do poder vigente para seu grupo de resistência.

\footnotetext{
${ }^{11}$ Este termo foi pego emprestado da crítica horaciana, que vê alguns poemas do autor romano nos quais se narra algum acontecimento futuro (normalmente, as mazelas do envelhecimento) como uma espécie de ameaça para se conseguir algo desejado (via de regra, o amor de uma mulher mais jovem) (Achcar, 1994). No caso em questão, entende-se que a própria distopia funcione como Profecia Ameaçadora ou melhor como "aviso de incêndio", na expressão de Leomir Hilário (2013, p. 206-207), como se verá, de modo a alertar o leitor para um risco futuro, mas iminente, normalmente de caráter político.
} 
Raazi, a outra protagonista, também é uma serva, mas da raça kaorsh. Juntamente com Yanisha, sua esposa, e sem ter conhecimento das ações contra o governo orquestradas por Aparição, Raazi trama um atentado contra a vida de Una, após Yanisha ter testemunhado mentiras e tramoias da governante. Percebendo que as coisas não são exatamente como foram contadas, começam a questionar a própria História de seu mundo - e, por consequência, a "teogonia" antes analisada - e terminam por provar que há algo de podre no reino de Untherak.

A partir dessas duas personagens, cuja motivação tanto evoca a dos personagens de distopias, percebe-se também outras divergências em relação às Fantasias tradicionais.

Uma diferença na trajetória de Aelian, por exemplo, se comparada à de outros protagonistas de fantasias mais ligadas à noção de "jornada do herói”, é o modo como um servo comum envolve-se na trama de modo totalmente justificável pelo encadeamento de acontecimentos, sem explicações mágicas (como profecias), genéticas (ele não descende de ninguém em especial) ou qualquer outro recurso deus ex machina habitual. Ou seja, sua narrativa acontece sem todo o peso advindo da ideia de um "herói escolhido", visível, por exemplo, nas séries Mago, de Raymond E. Feist, Shannara, de Terry Brooks, sem falar de Harry Potter, Percy Jackson e tantas outras. Ao mesmo tempo, não é uma história de múltiplos enredos, como As Crônicas do Gelo e do Fogo, de Martin, ou O Livro Malazano dos Caídos, de Steven Erikson, mas a de um grupo pequeno de heróis bastante questionáveis, os quais, por acaso ou por revolta, se veem embrenhados numa trama para mudar sua sociedade.

Da mesma forma, Raazi não tem as motivações mais comuns; não é movida por desejo de vingança ou de poder; apenas por uma busca pela verdade e pela igualdade, de uma forma bastante altruísta. Consciente de que seu plano é suicida, faz isso pelos que ficam, desejando mudar o mundo e a história por estar cansada de sentir e ver sofrimento. É uma idealista cuja obsessão se traduz em romper o ciclo de tirania imposta pela teocracia. Raazi e sua esposa, portanto, evocam mais o espírito das distopias do que das fantasias antes mencionadas. Unidas contra um governo escondido por trás da Máscara de um deus, as personagens de Ordem vermelha lembram mais as de Ninguém nasce herói, de Eric Novello, por exemplo, ou de Fahrenheit 451, de Bradbury, como citou-se anteriormente, do que a Sociedade do Anel tolkieniana ou as casas nobres de Westeros.

Dito isso, espera-se, portanto, ter mostrado o quanto a obra de Felipe Castilho, insere-se no modo narrativo da fantasia, mesmo enquanto o modifica, ao incluir também elementos da distopia, que permeiam toda a trama. Assim sendo, dialoga com o momento histórico e social do Brasil contemporâneo de maneira pertinente e com apurado rigor estético, atualizando o conceito de Fantasia para as conjunturas da época e conferindo-lhe certa cor local a partir do espaço de produção, apesar de o livro se passar em um mundo secundário, numa inovadora "fantasia distópica".

Isso é sintomático em um momento no qual a fantasia - por muito tempo vista como uma literatura alienada - ganha especial destaque no cenário atual por ser uma das vertentes mais produzidas, consumidas e comercializadas, para não dizer lucrativas. Pois, apesar de ser, dentre as diversas vertentes do que a crítica brasileira atual convencionou chamar de "insólito ficcional", a mais profícua, sendo inclusive uma das poucas categorias do modo fantástico (visto como macrocategoria) a ser publicado por grandes editoras, a fantasia permanece pouquíssimo estudada pela academia nacional.

Enquanto o horror, o gótico e o realismo mágico, para citar apenas algumas vertentes mais populares na crítica, são explorados em livros, teses, artigos e dissertações, ainda são poucos e pontuais os trabalhos dedicados à fantasia e suas subdivisões. Mesmo a ficção científica, por tanto tempo ignorada pela crítica brasileira e até hoje vista como "a prima pobre" do fantástico pelo mercado editorial, hoje é investigada em suas mais variadas nuances, em reconhecimento a seu potencial estético e reflexivo; não são poucos os estudos sobre cyberpunk e distopias, por exemplo. Já a fantasia, quando estudada, é comumente reduzida a seus representantes mais canônicos (como C. S. Lewis e J. R. R. Tolkien) ou, mais recentemente, àqueles com grande impacto na contemporaneidade (como George R. R. Martin e J. K. Rowling), com foco massivo na ficção de língua inglesa, ou ainda meramente enquanto fenômeno de sucesso comercial, viés relevante, mas que, se único, oblitera seu potencial artístico. 
Por sua vez, a fantasia brasileira especificamente permanece um território quase inexplorado, a despeito de sua prolífica produção, como se comentou acima. Por isso, falar dessa categoria a partir de Ordem vermelha: filhos da degradação é sintomático para a cena atual, tanto pelo viés do campo literário, quanto pelo olhar do mercado. Trata-se de uma obra bastante recente, de grande qualidade estética e narrativa, como se procurou mostrar e defender neste ensaio, que chega a público com imenso apoio institucional, algo pioneiro e incomum no mercado literário brasileiro. Lançado como grande destaque da ComicCon Experience 2017, o maior evento de cultura pop do país, e como aposta de uma imensa casa editorial, a Intrínseca, em cujo catálogo não havia antes obras fantásticas de autores nacionais, o livro Filhos da degradação aponta possíveis mudanças nesse cenário.

\section{Referências}

ACHCAR, Francisco (1994). Lírica e Lugar-Comum - Alguns Temas de Horácio e sua presença em Português. São Paulo: Editora da Universidade de São Paulo.

BAßLER, Moritz (2016). Realismo, serialidade e fantástico. Variedades da narrativa de língua alemã na atualidade. Tradução de Valéria Sabrina Pereira. Pandaemonium germanicum, São Paulo, vol. 19, n. 27, p. 77102. Disponível em: https://goo.gl/RRd57Q. Acesso em: 31 dez. 2017.

CASTILHO, Felipe (2017a). Cidade de Deus em Westeros. Revista Omelete Box, São Paulo, ano 1, n. 5, p. 40-43, dez.

CASTILHO, Felipe (2017b). Ordem vermelha: filhos da degradação. Rio de Janeiro: Intrínseca.

CESERANI, Remo (2006). O fantástico. Tradução de Nilton Cezar Tridapalli. Curitiba: UFPR.

HILÁRIO, Leomir Cardoso (2013). Teoria Crítica e Literatura: a distopia como ferramenta de análise radical da modernidade. Anuário de Literatura, Florianópolis, v. 18, n. 2, p. 201-215. Disponível em: https://goo.gl/4L6bfy. Acesso em: 31 dez. 2017.

KLEIN, Gérard (2009). Fiç̧ão Científica. In: RIOT-SARCEY, Michèle; BOUCHET, Thomas; PICON, Antoine. Dicionário das Utopias. Tradução de Carla B. Gamboa e Tiago Marques. Lisboa: Texto \& Grafia, p. 123-127.

LESSING, Gotthold Ephraim (2011). Laocoonte ou sobre as fronteiras da Pintura e da Poesia. Introdução, tradução e notas de Márcio Seligmann-Silva. São Paulo: Iluminuras.

LEWIS, C. S. (2005). As Crônicas de Nárnia. Tradução de Paulo Mendes Campos e Silêda Steuernagel. São Paulo: Martins Fontes.

MACHADO, Samir Machado de (2016). Homens elegantes. São Paulo: Rocco.

MANGUEL, Alberto (2013). Prefácio à Edição Portuguesa. In: MANGUEL, Alberto; GUADALUPI, Gianni. Dicionário de lugares imaginários. Tradução de Carlos Vaz Marques e Ana Falcão Bastos. Lisboa: Tinta da China, p. xi-xxxi.

MARQUES, Mirane Campos (2015). Uma história que não tem fim: um estudo sobre a fantasia literária. Tese (Doutorado em Letras) - Instituto de Biociências, Letras e Ciências Exatas, Universidade Estadual Paulista, São José dos Campos.

MARTIN, George R. R.; GARCÍA JR., Elio M.; ANTONSSON, Linda (2014). O Mundo de Gelo \& Fogo: A hstória não contada de Westeros e As Crônicas de Gelo e Fogo. São Paulo: LeYa.

MATANGRANO, Bruno Anselmi (2014). Entrevista com o Professor Flavio García acerca da literatura Insólita em Língua Portuguesa. Revista Desassossego, São Paulo, n. 11, p. 180-187. Disponível em: https://goo.gl/mb5ZrZ. Acesso em: 31 dez. 2017.

MATANGRANO, Bruno Anselmi (2016). O olhar contemporâneo na releitura do moderno: A lição de anatomia do temível Dr. Louison. Estudos de Literatura Brasileira Contemporânea, Brasília, n. 48, p. 247-280. Disponível em: https://goo.gl/Qy44vK. Acesso em: 31 dez. 2017. 
MATANGRANO, Bruno Anselmi (2018). Entrevista com o escritor Felipe Castilho. Jornal O Extra, Fernandópolis/SP, Caderno Cultura, Edição 3220, 27 jan. 2018. Disponível em: https://goo.gl/1UVisR. Acesso em: 23 jun. 2018.

MATANGRANO, Bruno Anselmi; TAVARES, Enéias (2018). Fantástico Brasileiro: o insólito literário do romantismo ao fantasismo. Curitiba: Arte \& Letra, 2018.

MOUCHARD, Claude (2009). Contra-Utopias. In: RIOT-SARCEY, Michèle; BOUCHET, Thomas; PICON, Antoine. Dicionário das Utopias. Tradução de Carla B. Gamboa e Tiago Marques. Lisboa: Texto \& Grafia, p. 84-89.

NOGUEIRA FILHO, Carlos Alberto (2013). Dimensões do fantástico e aventuras da tradução em The Lord of the Rings, de J. R. R. Tolkien. Dissertação (Mestrado em Letras, Literatura e Crítica Literária) - Pontifícia Universidade Católica de Goiás, Goiânia.

NOVELLO, Eric (2017). Ninguém nasce herói. São Paulo: Seguinte.

PROPP, Vladimir (2010). Morfologia do conto maravilhoso. Rio de Janeiro: Forense Universitária.

THIÉS, Tainá Siqueira (2012). A transposição do real para o imaginário: hipertextualidade mitológica na construção de mundos ficcionais de fantasia. Dissertação (Mestrado em Literatura e Práticas Sociais) Instituto de Letras, Universidade de Brasília, Brasília.

TODOROV, Tzvetan (2008). Introdução à Literatura Fantástica. Tradução de Maria Clara Castello. São Paulo: Perspectiva.

TOLKIEN, J. R. R. (1999). O silmarillion. Tradução de Waldéa Barcellos. São Paulo: Martins Fontes.

WUNENBURGUER, Jean-Jacques (2003). L'Imaginaire. Paris: PUF. 